\title{
Prescription Drug Use Among Elderly and Nonelderly Families
}

PATRICK L. MCKERCHER, PhD; STEPHANIE D. TAYLOR, PhD;

JAMES A. LEE, MS; JINGDONG CHAO, MS; and RITESH N. KUMAR, MS

\begin{abstract}
OBJECTIVE: This study augments existing literature by examining characteristics associated with prescription drug utilization and makes an in-depth assessment of family prescription drug economic burden within the United States. The objective of this study was to examine differences in prescription drug use and prescription drug characteristics among elderly and nonelderly families.
\end{abstract}

METHODS: A measure of out-of-pocket prescription drug burden associated with family prescription drug utilization was constructed using data from the 1996 Medical Expenditure Panel Survey (MEPS). Families were designated as the unit of analysis and further divided by age ( $<65$ and $\geq 65$ years) of the reference person. The 1996 MEPS database provides medical expenditure data on a national sample of 8,917 families (22,601 individuals) and 147,308 drug episodes, i.e., prescription procurement. The ratio of family prescription out-of-pocket expenditures to family income was used to assign families to economic burden rank-ordered quintiles, each representing $20 \%$ of U.S. families in 1996 .

RESULTS: Prescription size, price, and drug use were higher among elderly families. Their proportion of generic use was higher compared to nonelderly families. Additionally, out-of-pocket prescription expenditures represented $23.7 \%$ and $45.6 \%$ of the total out-of-pocket medical care burden for nonelderly and elderly families, respectively. The average prescription drug burden (total prescription out-of-pocket costs/family income) was $0.4 \%$ for nonelderly and $1.9 \%$ for elderly households.

CONCLUSION: The study results demonstrate an ability to identify populations with high economic burden for prescription medications. The presumption is that persons age 65 or older, lacking purchasing leverage, are more likely to pay full retail price and, consequently, higher prices. Our findings suggest that high prescription drug burden was a function of prescription size and cost per prescription, with prescription size showing more drastic differences between the high and low prescription drug burden subgroups. Future studies should continue to assess factors influencing families' prescription drug economic burden, and the information derived from these studies should be used by benefit planners in designing drug benefits within health insurance plans.

KEYWORDS: Out-of-pocket costs, Health status, and Generic drug use

J Managed Care Pharm. 2003(9)1: 19-28

\section{Authors}

PATRICK L. MCKERCHER, PhD, is Director, Center for Medication Use, Policy and Economics; STEPHANIE D. TAYLOR, PhD, is Assistant Professor; JAMES A. LEE, MS, is Research Associate, Center for Medication Use, Policy, and Economics; JINGDONG CHAO, MS, is a Graduate Student; and RITESH N. KUMAR, MS, is a Graduate Student, all at the College of Pharmacy, University of Michigan, Ann Arbor.

AUTHOR CORRESPONDENCE: Stephanie D. Taylor, PhD, Assistant Professor, College of Pharmacy, University of Michigan, 428 Church St., Ann Arbor, MI 48109-1065. Tel: (734)647-5483; Fax: (734)615-8171; E-mail: sdtaylor@umich.edu

Copyright $\odot$ 2003, Academy of Managed Care Pharmacy. All rights reserved.
$\mathrm{P}$ erhaps one of the most enduring debates in social policy surrounds the addition of a prescription drug benefit to the Medicare program. These debates have been ongoing since the inception of the Medicare program some 35 years ago. ${ }^{1}$ Advocates for prescription drug coverage argue that prescription medications should be covered to create a more comprehensive health care plan. Early opposition to prescription drug coverage was largely related to the minimal clinical benefits gained from the use of prescription drugs for treatment of chronic diseases during that time. However, today, the tremendous scientific breakthroughs in understanding the pathophysiology of diseases combined with the development of new pharmaceutical products make prescription drugs an effective form of treatment for acute and chronic conditions. ${ }^{2}$ In this analysis, we examined characteristics of prescriptions associated with medication utilization among elderly and nonelderly families with different levels of prescription drug economic burden. We measured prescription drug economic burden as the ratio of out-of-pocket prescription drug expenditures to total family income.

\section{Background}

Experiences of receiving and paying for prescriptions are not the same for all consumers. For example, in 1997, uninsured persons aged $<65$ years spent an average $\$ 30.76$ out-of-pocket per prescription compared to an average $\$ 9.96$ spent by an insured person aged $<65$ years. ${ }^{3}$ Miller and Moeller reported differences in the retail cost of medications to consumers across disease categories and insurance groups using the Medical Expenditure Panel Survey (MEPS), the same dataset that is examined in the extant study. ${ }^{4}$ Uninsured individuals paid $16.5 \%$ higher prices for prescription drugs than did privately insured individuals. Particularly noteworthy is that $28.3 \%$ of prescriptions purchased by Medicare beneficiaries were not covered by insurance despite additional sources of coverage such as Medicare health maintenance organizations (HMOs). Poisal and Murray suggest that Medicare beneficiaries without prescription drug insurance often end up paying the highest price for drugs because they do not possess any bargaining power to gain discounts. ${ }^{5}$

The National Institute for Health Care Management Research and Educational Foundation reported that spending on retail outpatient prescription drugs increased by $18.8 \%$ in 2000 , from $\$ 111.1$ billion to $\$ 131.9$ billion. ${ }^{6}$ On average, in 1996, consumers purchased 6.94 prescriptions in that calendar year and paid about $\$ 35$ per prescription. While prescription drugs were second to dental services in the proportion of cost borne by the consumer, $44.5 \%$ versus $51.5 \%$, the burden of 
prescription drug purchases is more economically significant among the elderly because pharmaceuticals represented a greater proportion of health care expenditures, $12.9 \%$ versus $7.8 \%$ for dental services. ${ }^{7}$ A uniqueness of prescription drug expenditures is that in 1996, they represented about $13.0 \%$ of total health care expenditures. Moreover, $45 \%$ of the prescription costs were out-of-pocket spending by the consumer through self-pay for the medication, and cost-sharing requirements, including deductibles, copayments, and prescriptions obtained after expenditure caps are exceeded. In contrast, approximately $18 \%$ of total medical expenses were borne by the consumer in $1996 .{ }^{8}$ Cost sharing was disproportionately higher for prescription drugs. Prescription medication expenditures represent an extremely skewed distribution of costs borne by consumers since a small subset of the population incurs exceptionally high out-of-pocket expenditures. ${ }^{9}$

Several studies highlight the fact that persons aged $>65$ years are more vulnerable to medication costs. Older persons experience a greater prevalence of chronic diseases and, hence, consume more medications than their younger counterparts. ${ }^{10-13}$ In a study of the financial burden of prescription drugs, persons aged $\geq 65$ years with chronic conditions experienced a higher burden than those without chronic conditions. Those with diabetes spent an average of $4.1 \%$ of their household income, and persons with conditions such as heart failure, angina, and ulcers spent between $3.7 \%$ and $3.9 \%$ of their household income on prescription drugs. ${ }^{14}$

Crystal et al. analyzed out-of-pocket health care expenditures in relation to individual or couples income using data from the Medicare Current Beneficiary Survey (MCBS). ${ }^{15}$ Total out-of-pocket health care expenditures averaged 19\% of income for Medicare beneficiaries during 1995. Higher-burden subgroups included beneficiaries in poor health, spending $28.5 \%$ of income; beneficiaries older than 85 years, spending $22.4 \%$ of income; and beneficiaries with income levels in the lowest quintile, including those with Medicaid coverage, spending $31.5 \%$ of income. Medicare beneficiaries in fee-for-service programs averaged $23 \%$ of income in payment for health care services, and those with self-purchased supplemental insurance averaged $25.5 \%$ of income. Beneficiaries possessing employersponsored coverage or who were enrolled in HMO's experienced lower burden rates. The 2 highest out-of-pocket health expenditure categories were for medical services at $35.1 \%$, followed by prescription medications at $33.9 \% .^{15}$

There is evidence that out-of-pocket prescription drug costs contribute significantly to the health care economic burden. Gross et al. evaluated out-of-pocket health care spending by poor and near-poor Medicare beneficiaries. ${ }^{16}$ These consumers spent approximately half of their income on out-of-pocket health care expenditures. Beneficiaries with incomes between $100 \%$ and $125 \%$ of the federal poverty level spent an estimated $30 \%$ of their income on health care if they were enrolled in traditional Medicare and 23\% if they were enrolled in a Medicare
HMO. An interesting observation is that almost 60\% of Medicare beneficiaries with incomes below the federal poverty level did not receive Medicaid assistance in 1997. Therefore, we cannot assume that Medicare beneficiaries with lower incomes have prescription drug coverage through Medicaid programs. The lack of Medicaid coverage would further exaggerate the influence of out-of-pocket expenditures for prescription drugs on overall health care economic burden.

Almost 2.5 million Medicare beneficiaries (30\%) lacked prescription drug coverage and spent an average of approximately $\$ 546$ out-of-pocket in 1998 compared to $\$ 325$ spent by beneficiaries aged $\geq 65$ years with private or public drug insurance. ${ }^{5}$ Lillard, Rogowski, and Kington examined the effects of prescription drug insurance coverage on medication use and expenditures among the respondents aged $\geq 65$ years. ${ }^{17}$ Coverage significantly increased the likelihood of use, but not of total expenditures, among those who used prescription drugs. Insurance coverage also lowered out-of-pocket expenditures, consequently decreasing the financial burden on households with respondents aged $\geq 65$ years. Insurance coverage for drugs significantly reduced the fraction of household income spent on prescription drugs by $50 \%$, thereby reducing the family burden. ${ }^{14}$

The bulk of existing literature suggests that those persons aged $\geq 65$ years are significantly burdened, i.e., a large percentage of their household income is dedicated to out-of-pocket prescription drug expenditures. One contradictory indicator of potential excessive burden is the proportion of persons leaving prescriptions unfilled for cost or affordability reasons. Data from the MCBS do not confirm the assumption ${ }^{18}$ that elderly individuals are going without medications, and there is evidence suggesting that families with persons aged $<65$ years, rather than older families, are less able to afford prescription drugs than their counterparts aged $\geq 65$ years. ${ }^{19}$

\section{Methods \\ Unit of Analysis}

Many studies treat economic burden as a measure of hardship, financial risk, or liability. In these studies, economic burden has been used to illustrate the vulnerability of individual consumers and their subsequent need for a prescription drug benefit. ${ }^{14-16}$ However, health and medical benefits are generally available to dependents of insured employees, and out-of-pocket expenditures borne by an individual family member often draws upon family household resources. Based on this assumption, we posit that the burden associated with out-of-pocket expenditures is a family burden. In this research, family units were the primary unit of analysis for measures of out-of-pocket expenditures and resources available. (Burden and income for families with a reference person aged $\geq 65$ years would differ from the combined income and burden for a couple aged $\geq 65$ years since families could include dependents or income from family members aged $<65$ years.) Family was defined as any persons living together 
and related to one another by blood, marriage, adoption, foster care, or self-identified as a single unit plus related students who are living away at postsecondary school. ${ }^{20}$ In the analysis of prescription drug characteristics, individual prescriptions were the unit of analysis.

\section{Data Source}

Data from the Household Component and Prescription Drug Event public use files from the 1996 MEPS database were analyzed in this study. MEPS is a nationally representative survey of health care use including medications, expenditures, sources of payment, and insurance coverage for the U.S. civilian noninstitutionalized population. ${ }^{20}$ All estimates are weighted to be representative of the U.S. population. The MEPS sample is a subsample of the 42,000 families included in the National Household Interview Survey. Families with missing data, such as age or income of the reference person, were excluded. Of the 8,917 family units in the 1996 MEPS sample, 418 (4.7\%) were excluded by these criteria, resulting in a sample of 8,499 families, including 21,849 of the 22,601 individuals and 145,531 (99\%) of the 147,308 prescriptions in the database. Rates of drug use are reported using the total sample, excluding 418 families with missing essential data. In other words, the denominator includes both prescription drug users and nonusers. A cross-sectional analysis was conducted using family-level data, and for some variables such as health status, individual level values were used to construct the family value.

The Prescribed Medication file is unique to MEPS because a pharmacy follow-back survey was used to verify prescription drug use. Prescription drug information was obtained from pharmacy providers frequented by household-sampled persons. The verification process attempted to obtain information for filled and refilled prescription medications. Each pharmacy was asked to provide the following information for each prescription: date the prescription was filled or refilled, the national drug code (NDC), medication name (generic or brand), medication strength, quantity dispensed, total charge, source of payment, and the amount of payment made by each source. Approximately 67\% of the household patient-prescription pairs were verified. Further details of the verification methodology are described elsewhere. ${ }^{21}$

MEPS captures the NDC for prescriptions dispensed, while other surveys rely on self-reported descriptions of the medication used. By using NDC-coded data, we were able to explore the prescription characteristics such as generic versus brand name. Additionally, an advantage of the MEPS database over other national expenditure surveys such as MCBS is the availability of data for both individuals and households with persons aged $<65$ years and $\geq 65$ years. Details on the database are described elsewhere. ${ }^{20}$

\section{Measures}

Family prescription drug economic burden. The economic burden of health care expenditures was measured as the ratio of family out-of-pocket health care costs to family income. Versions of this ratio, including individual burden rates, have been used to highlight the need for financial protection against high medical expenditures. ${ }^{17,22}$ Prescription drug-specific economic burden scores were calculated by dividing the total family out-of-pocket prescription costs by total family income. Outof-pocket costs consist of payments for prescription medications such as deductibles, copayments, and the costs for prescriptions obtained after the expenditure cap is exceeded. Prescription drug insurance premium payments were not included in the cost burden associated with prescription drugs.

The Consumer Expenditure Survey's (CES's) definition of family income was used. ${ }^{23}$ The definition of family income includes wages and salaries; self-employment income; Social Security, private and government retirement; interest, dividends, rental income, and other property income; unemployment, workers' compensation and veteran's benefits; public assistance, supplemental security income, food stamps; regular contributions for support (including alimony and child support); other income (including cash scholarships, fellowships, or stipends not based on working, and meals and rent as pay).

Prescription drug characteristics. Prescription information such as number of medications was based on drug episodes reported. All prescriptions attributable to any individual with reported age were sorted in subgroups of persons aged $<65$ years and $\geq 65$ years. Prescription-specific information was achieved by linking NDCs for each episode with U.S. Food and Drug Administration product identification using Multum, ${ }^{24}$ a proprietary product used for assigning medications to generic/brand, "Orange Book," bioequivalency, and therapeutic categories.

Family health status. Family health status was assigned by examining each family member and flagging any member reporting fair or poor health status during the calendar year. Therefore, this value represents the percentage of families with at least one individual reporting fair or poor health status. The lowest health status score a person reported in any data collection rounds during a year was chosen regardless of the health status reported in other rounds. The health status variable was constructed using the lower values "fair" or "poor" to assign a low health status to the family.

Family economic barriers. Access to care for a family was determined if any member of the family answered "yes" to questions assessing whether cost was responsible for (1) having difficulty receiving care, (2) not being able to afford the care, or (3) if someone in the family went without care. The percentage of families with at least one person responding yes to any of the 3 economic barrier questions were analyzed for each burden quintile.

Family insurance status. Health insurance status of individuals within a family was determined based on mutually exclusive family coverage categories. The insurance categories were private, public only, and uninsured. Prescription drug insurance is not available in the MEPS public data file. As a result, a proxy measure of prescription drug insurance status 
TABLE 1 Prescription Drug Use Among Families*

\begin{tabular}{|c|c|c|c|}
\hline & $\begin{array}{l}\text { All Family Units } \\
\qquad \mathrm{N}=8,499 \dagger\end{array}$ & $\begin{array}{c}\text { Family Units } \\
\text { Age }<65 \\
\mathrm{~N}=6,768\end{array}$ & $\begin{array}{c}\text { Family Units } \\
\text { Age } \geq 65 \\
N=1,680\end{array}$ \\
\hline \multicolumn{4}{|l|}{ Drug Expenditures } \\
\hline Family OOP $\ddagger \mathrm{Rx}$ expenditures & $\$ 247.72$ & $\$ 178.93$ & $\$ 524.11$ \\
\hline Family income & $\$ 42,378$ & $\$ 46,242$ & $\$ 27,982$ \\
\hline Family OOP Rx expenditures/income & $0.58 \%$ & $0.39 \%$ & $1.87 \%$ \\
\hline Family size & 2.4 & 2.6 & 1.7 \\
\hline Age of household reference person & 46.9 & 40.3 & 74.6 \\
\hline Families with at least one $\mathrm{Rx}$ & $83.5 \%$ & $81.9 \%$ & $85.1 \%$ \\
\hline Number of Rx's & 16.1 & 13.2 & 28.0 \\
\hline Family Rx expenditures & $\$ 563$ & $\$ 448$ & $\$ 1,028$ \\
\hline Share of Rx expenditures OOP & $44 \%$ & $40 \%$ & $51 \%$ \\
\hline Share of families with $100 \%$ Rx OOP§ & $15.6 \%$ & $15.3 \%$ & $16.6 \%$ \\
\hline OOP Rx as $\%$ of total OOP Health care & $29.5 \%$ & $23.7 \%$ & $45.6 \%$ \\
\hline Rx Use\| & $N=147,308$ & $\mathrm{~N}=97,234$ & $\mathrm{~N}=48,297$ \\
\hline Generic RxIl & $37.9 \%$ & $38.1 \%$ & $37.5 \%$ \\
\hline Generic Rx expenditures & $19.3 \%$ & $18.7 \%$ & $20.5 \%$ \\
\hline Retail cost per Rx & $\$ 35.00$ & $\$ 34.38$ & $\$ 36.34$ \\
\hline Rx Size (number of dose units) & 56.8 & 55.4 & 59.6 \\
\hline Retail cost per dose unit & $\$ 0.62$ & $\$ 0.62$ & $\$ 0.61$ \\
\hline \multicolumn{4}{|c|}{$\begin{array}{l}\text { Source: } 1996 \text { Medical Expenditure Panel Survey (MEPS) - April } 2001 \text { release. } \\
\text { * Where appropriate, the family average is reported. } \\
\dagger \text { Family units subdivided based on age of reference person; } 51 \text { families did not report a reference person with age. } \\
\text { † OOP: out-of-pocket. } \\
\text { \& Families with no evidence of Rx coverage. } \\
\text { \|I Unit of analysis for shaded values is prescriptions rather than family units. } \\
\mathbb{I} 2,177 \text { prescription NDC codes did not match brand versus generic classification. }\end{array}$} \\
\hline
\end{tabular}

was constructed. Families with no evidence of payment by insurance companies for prescription medications (total cost = self pay) were categorized as lacking a prescription drug benefit, and those with any evidence of third-party payment of prescription drugs were categorized as having a prescription drug benefit.

\section{Data Analysis}

For the bulk of the analyses, the surveyed population was divided into 2 family subsamples based on the age $(<65$ years and $>65$ years) of the family reference person. Family-level weights provided by MEPS were used in the analyses. The use of weights allows us to project national estimates for the civilian noninstitutionalized U.S. population for 1996 for the variables of interest. The 2 subsamples, based on the age of the reference person for families and personal age for individuals, were ordered by prescription drug burden scores and assigned to one of 5 quintile categories. Those families with prescription drug economic burden scores in the 20th percentile or less were considered as the "low-burden" group. Families with economic burden scores between the 40th and 60th percentile range were considered to have a "middle burden," and those with prescription drug burden scores in the 80th percentile or higher range were considered to be families with "high burden." Comparisons were drawn of prescription drug characteristics between quintile groups.

\section{Results}

The prescription drug use among families and prescription use characteristics are presented in Table 1 and Figure 1, respectively. This analysis examined 145,531 prescriptions used by 8,499 of the total 8,917 families in the 1996 MEPS database. Variables were weighted such that values represent estimates for slightly more than 4 million families with members aged $\geq 65$ years in each of the quintiles and more than 16 million 
families with members aged $<65$ years. For the 8,499 families in the final sample, the average prescription drug out-of pocket expenditure was $\$ 247.72$ or $29.5 \%$ of total out-of-pocket expenditures for health care. As shown in Table 1, the elderly families' prescription drug expenditures represented $45.6 \%$ of the total out-of-pocket expenditures for health care versus $23.7 \%$ for the nonelderly families.

The average personal incomes were similar for persons aged $\geq 65$ years and $<65$ years, $\$ 17,786$ versus $\$ 17,386$; however, household or family incomes differed substantially, $\$ 27,982$ versus $\$ 46,242$, respectively. The average family with the reference person aged 65 years and older spent $\$ 1,028$ for medications, with $\$ 524$ coming from family out-ofpocket resources. Elderly or families with members aged $\geq 65$ years had higher prescription drug expenditures; their share of out-of pocket prescription drug expenditures was $51 \%$ versus $40 \%$ for the nonelderly families.

Overall, families with any form of public insurance averaged the highest number of prescriptions, 13.4 prescriptions compared to 11.9 prescriptions for privately insured and 6.9 prescription for uninsured families. The families with members aged $\geq 65$ years accounted for a disproportionate share of prescriptions, with $12.6 \%$ of the sample accounting for slightly less than one third of all prescriptions. For elderly families, the average prescription was priced $5.7 \%$ higher and had $7.6 \%$ more doses. Cost per dose was approximately equivalent for elderly and nonelderly families when adjusted for prescription size. On average, the retail cost per dose was about 3\% lower, which is a reflection of a larger prescription size, resulting in lower costs per dose, and higher proportion of expenditures represented by generic drugs.

\section{Prescription Drug Burden}

Prescription drug characteristics and expenditures across the low-, middle-, and high-burden quintile groups are presented in Table 2. The out-of-pocket prescription drug expenditures in the low- to high-burden quintiles ranged from $\$ 21$ to $\$ 1,476$. The corresponding prescription drug burdens ranged from $0.06 \%$ to $9.9 \%$ for the families with members aged $\geq 65$ years and from $0.0 \%$ to $2.0 \%$ for families with members aged $<65$ years.

Prescription drug burden represented about 1\% of income for the general population. ${ }^{25}$ In this sample, this breaks down to $0.39 \%$ for households with persons aged $<65$ years and $1.87 \%$ for those with persons aged $\geq 65$ years (Table 1 ). However, the distribution of almost all statistics is highly skewed, with a small proportion of individuals experiencing exceptionally high use and expenditures. For example, households with persons aged $\geq 65$ years in the highest-burden quintile averaged $9.9 \% .^{15}$
After families were assigned to quintiles, total economic and prescription drug burden ratios were reported as the ratio of the means within the respective categories rather than the average of individual family means. In other words, the subtotal average expenditures were divided by the subtotal average income within each quintile. This mimics the methods used by Crystal et al. and minimizes the distortion caused by extreme scores in this skewed distribution of scores. ${ }^{15}$

In this analysis, the data were not censored and included extreme values that were excluded as outliers in other studies. For example, some researchers top capped expenses at 100\% of income on the assumption that resources other than income were used to cover prescription drug expenditures. ${ }^{15,16}$ In our analysis, there were 13 families with prescription drug burden exceeding $100 \%$ of income (one with only $\$ 20$ annual income) who were legitimate families representing legitimate expenditures. These families would be dramatically impacted by maximum expenditure caps, and they also influence overall prescription drug burden rates, which were sensitive to extreme scores. Prescription drug burden rates for the highest quintile were higher than they would have been if families with extreme values were excluded. Different methods and the effect of calculating economic burden using ratio of the means versus average of the means are illustrated in Table 3. Based on the analyses, the economic burden was higher for elderly families than nonelderly families irrespective of calculation method.

In Table 4, the differences in medical expenditures, health status, and economic barriers by burden quintiles are summarized. An advantage of using the prescription drug-specific ratio, prescription drug burden, is the ability to examine prescription drug out-of-pocket burden in relationship to the total health care burden. Part of the explanation for the attention to prescription drug burden is the impact on the population older than $\geq 65$ years. Because this population is covered by Medicare, which does not cover medications, the total medical 
Prescription Drug Use Among Elderly and Nonelderly Families

TABLE 2 Prescription Drug Use Among Families by Age and Burden Level*

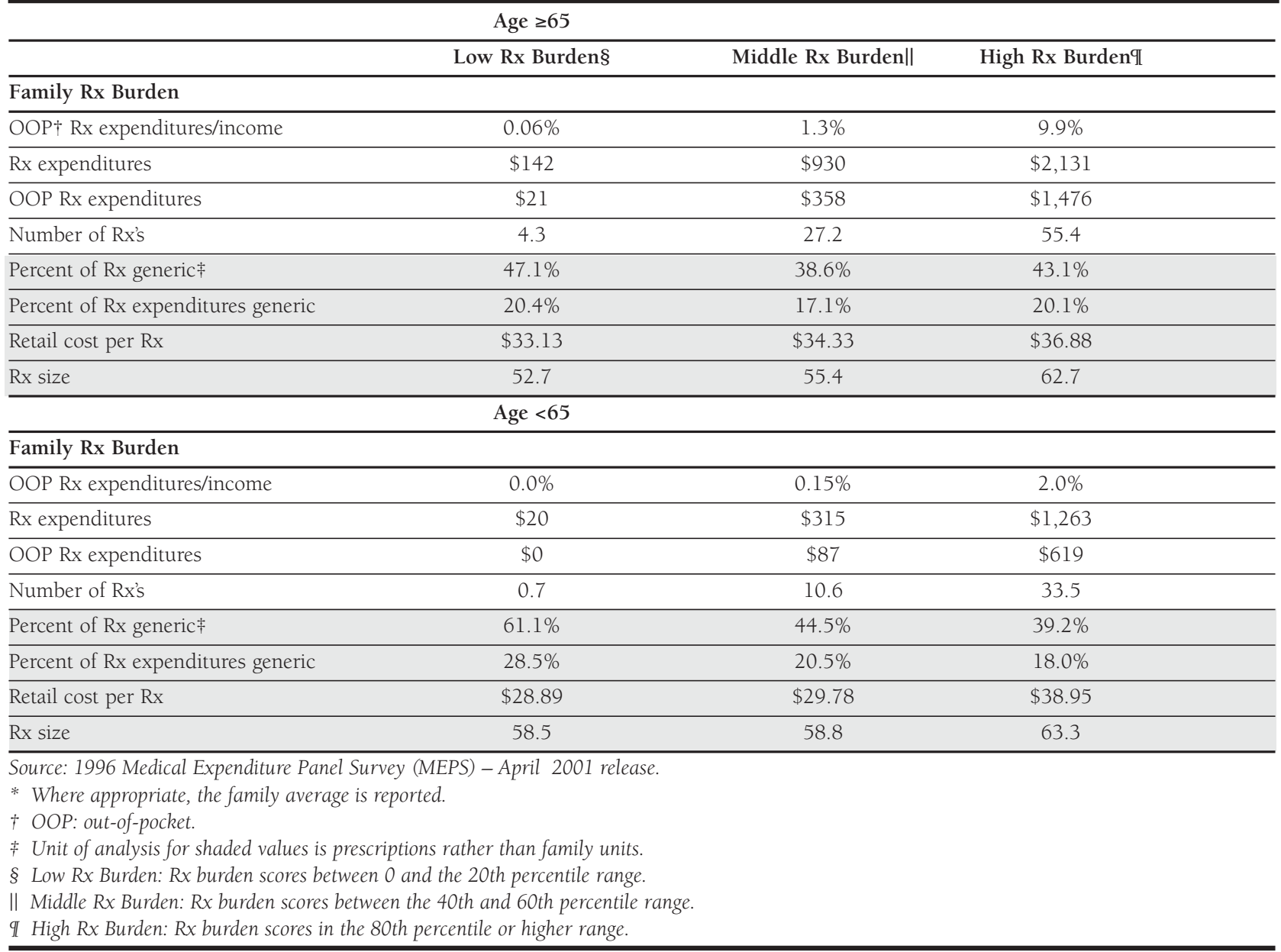

economic burden decreases while the prescription drug burden increases, amplifying the significance of that burden.

Health status in the families with members aged $\geq 65$ years was lower. Fifty-one percent of families had low health status in the high-burden quintile compared to $20 \%$ of families in the low-burden quintile. Families with $100 \%$ self-pay were used as a proxy for families with no prescription drug insurance. On average, 15.6\% of families lacked prescription drug insurance. The incidence of no insurance was highest among the high-burden group for both elderly (19.6\%) and nonelderly (15.2\%) families. A similar relationship existed with barriers to health care in which a higher percentage of families in both the elderly and nonelderly high-burden groups responded "yes" to having experienced economic barriers to health care (Table 4).

\section{Generic Drug Use}

Generic use was highest among low prescription drug-burden families (61.1\% of prescriptions), and differences between lowand high-burden families were greater in the families with members aged $<65$ years (Table 2). Generic expenditures for the elderly families were consistent across quintiles. In the lowburden families with members aged $\geq 65$ years, this was $20.4 \%$ versus $20.1 \%$ in the high-burden families with members aged $\geq 65$ years. However, the percentages of generic expenditures in the nonelderly families were dramatically different. In the lowburden families, $28.5 \%$ of expenditures were for generics compared to $18 \%$ in the high-burden nonelderly families. Generic drug use was highest for antimicrobial pharmaceuticals. ${ }^{4}$ One possible explanation for highest generic drug use among families with members aged $<65$ years in the lowest prescription drug-burden quintile is that, in these families, medication use is less frequent and more often for acute care (for example, use of antibiotic drugs among children). Retail cost per prescription and cost per dose were lowest in this group.

24 Journal of Managed Care Pharmacy JMCP January/February 2003 Vol. 9, No. 1 www.amcp.org 
Prescription Drug Use Among Elderly and Nonelderly Families

TABLE 3 Comparison of Average Rx Burden Scores With the Ratio of the Means

\begin{tabular}{|c|c|c|c|c|c|c|c|}
\hline & \multirow[b]{2}{*}{$\mathrm{N}$} & \multicolumn{2}{|c|}{ Total } & \multicolumn{2}{|c|}{ Age $<65$} & \multicolumn{2}{|c|}{ Age $\geq 65$} \\
\hline & & $\begin{array}{l}\text { Average of Rx } \\
\text { Burden Scores }\end{array}$ & $\begin{array}{c}\text { Ratio of } \\
\text { Average OOP* } \\
\text { Rx/Average } \\
\text { Income }\end{array}$ & $\begin{array}{l}\text { Average of Rx } \\
\text { Burden Scores }\end{array}$ & $\begin{array}{c}\text { Ratio of } \\
\text { Average OOP } \\
\text { Rx/Average } \\
\text { Income }\end{array}$ & $\begin{array}{l}\text { Average of Rx } \\
\text { Burden Scores }\end{array}$ & $\begin{array}{c}\text { Ratio of } \\
\text { Average OOP } \\
\text { Rx/Average } \\
\text { Income }\end{array}$ \\
\hline Person & 20,743 & $1.8 \%$ & $0.59 \%$ & $1.4 \%$ & $0.39 \%$ & $3.9 \%$ & $2.1 \%$ \\
\hline Family & 8,499 & $1.16 \%$ & $0.58 \%$ & $0.63 \%$ & $0.39 \%$ & $3.19 \%$ & $1.9 \%$ \\
\hline
\end{tabular}

Generic drug use among family units with members aged $\geq 65$ years did not differ across burden quintiles. The highest portion of generic drug use was in the lowest-burden group. The penetration of generic drug use in this population may be reaching the maximum opportunity level with all 3 burden groups using generic drugs to a greater extent than their younger counterparts. Generic drug use in the high-burden group with persons aged $<65$ years was lower than the low-burden group with persons aged $<65$ years in both proportion of prescriptions and proportion of expenditures (Table 2). Among those aged $\geq 65$ years, the proportion of generic prescriptions was lower in the high-burden group compared to the low-burden group.

\section{Discussion}

Central to this research is the profile of prescription drug use contrasting families with reference members aged $<65$ years and $\geq 65$ years and low, middle, and high prescription drugburdened families. Consistent with previous research, consumers aged $\geq 65$ years had higher average prescription costs and subsequent medication use. ${ }^{12-14}$ Families in the high prescription drug-burden group purchased more prescriptions and had higher out-of-pocket expenditures and higher total prescription drug expenditures. Since prescription drug burden is the ratio of out-of-pocket prescription drug expenditures to income, the scores varied across quintiles, as expected, with expenditures increasing and income decreasing with higher burden rates. The method selected for computing burden in this analysis, the ratio of average out-of-pocket prescription drug expenses to average earned income, is comparable to that used in previous studies. ${ }^{13,14}$

The economic burden of prescription expenditures calculated at the family level is closer to reality than personal expenditures since discretionary household income is likely to be directed toward the needs of any individual member incurring health care expenses regardless of personal income. The prescription drug-burden ratio standardizes the out-of-pocket costs based on income and represents the relative significance of out-of-pocket prescription costs incurred by families. For example, high-income families with exceptionally high out-ofpocket medication expenses can be as heavily burdened as lower-income families with modest expenditures.

Using the prescription drug-burden ratio to group families dispels some assumptions believed to be associated with outof-pocket burden. For example, the proportion of generic prescriptions among elderly families is relatively consistent across burden levels. However, the proportion of generics used in nonelderly families is related to burden levels with low-burden families using higher levels of generic prescriptions.

The relationship between health status and prescription drug burden is, as expected, inversely related. The proportion of family members indicating poor or fair health status is more than twice as prevalent in the high prescription drug-burden group compared to the low prescription drug-burden group (51\% versus $20 \%$ among families with reference person aged $\geq 65$ years). Finally, respondents were asked if they experienced an economic barrier to health care in general. This is not a direct measure of access to prescription medications but reveals an interesting disparity between elderly and nonelderly families, with the nonelderly experiencing higher levels of economic barriers, which is more pronounced in the high-burden families.

A notable observation is the escalation of average prescription cost across the prescription drug-burden quintiles. The number of prescriptions and share of prescription costs paid out-of-pocket for families were positively related to prescription drug burden. Insurance status was reported as medical insurance, in general, and not necessarily prescription drug coverage. Comparisons by insurance coverage were inconclusive. In an effort to assess prescription drug coverage, we counted the number of prescriptions paid entirely by the individual (total cost $=$ self pay) as a marker for no evidence of insurance coverage. The proportion of prescriptions paid by families without evidence of coverage is smaller than what might be expected. Possible explanations are that individuals have alternative sources of help, including clinics or prescription assistance programs not perceived as insurers. The relationship of this variable to prescription drug burden is consistent with expectations in the nonelderly population but not related to prescription drug burden in the elderly.

With the exception of insurance status, this analysis supports the assumption that prescription drug burden is related 
Prescription Drug Use Among Elderly and Nonelderly Families

TABLE 4 Health Care Use Among Families*

\begin{tabular}{|c|c|c|c|}
\hline \multicolumn{4}{|c|}{ Age $\geq 65$} \\
\hline & Low Rx Burden & Middle Rx Burden§ & High Rx Burden\| \\
\hline \multicolumn{4}{|l|}{ Medical Expenditures } \\
\hline Medical care burden & $1.2 \%$ & $4.1 \%$ & $14.7 \%$ \\
\hline Total medical expenditures & $\$ 2,423$ & $\$ 6,894$ & $\$ 11,926$ \\
\hline OOP $\dagger$ medical expenditures & $\$ 430$ & $\$ 1,158$ & $\$ 2,193$ \\
\hline \multicolumn{4}{|l|}{ Share of total OOP expenditures } \\
\hline attributable to $\mathrm{Rx}$ & $4.9 \%$ & $30.9 \%$ & $67.3 \%$ \\
\hline Perceived health status (fair or poor) & $20.2 \%$ & $28.0 \%$ & $51.3 \%$ \\
\hline \multicolumn{4}{|l|}{ Individuals responding "yes" to } \\
\hline \multirow[t]{2}{*}{ economic barrier to care } & $2.1 \%$ & $3.3 \%$ & $5.0 \%$ \\
\hline & Age $<65$ & & \\
\hline \multicolumn{4}{|l|}{ Medical Expenditures } \\
\hline Medical care burden & $.06 \%$ & $1.3 \%$ & $4.7 \%$ \\
\hline Total medical expenditures & $\$ 1,105$ & $\$ 3,826$ & $\$ 6,874$ \\
\hline OOP medical expenditures & $\$ 200$ & $\$ 727$ & $\$ 1,430$ \\
\hline \multicolumn{4}{|l|}{ Share of total OOP expenditures } \\
\hline attributable to $\mathrm{Rx}$ & $0.0 \%$ & $12 \%$ & $43.3 \%$ \\
\hline Perceived health status (fair or poor) & $7.2 \%$ & $8.1 \%$ & $25.7 \%$ \\
\hline \multicolumn{4}{|l|}{ Individuals responding "yes" to } \\
\hline economic barrier to care & $9.6 \%$ & $9.1 \%$ & $18.6 \%$ \\
\hline $\begin{array}{l}\text { Source: } 1996 \text { Medical Expenditure Pane } \\
\text { * Where appropriate, the family averag } \\
\dagger \text { OOP: out-of-pocket. } \\
\ddagger \text { Low Rx Burden: } R \times \text { burden scores bet } \\
\S \text { Middle Rx Burden: Rx burden scores } \\
\text { II High Rx Burden: Rx Burden scores in }\end{array}$ & $\begin{array}{l}\text { el Survey (MEPS) - } \\
\text { ge is reported. } \\
\text { tween } 0 \text { and the } 20 \text { th } \\
\text { between the } 40 \text { th and } \\
\text { the } 80 \text { th percentile } 0\end{array}$ & & \\
\hline
\end{tabular}

to income, number of prescriptions, health status, and total health expenditures. Prescription drug insurance coverage was not reported specifically, so inferences must be made from measures of medical insurance or evidence of self-pay.

\section{Limitations}

This is a cross-sectional research design and, consequently, contains no temporal ordering of information. Therefore, cause-and-effect relationships cannot be identified from the results. Additionally, with the cross-sectional design, trend analyses or forecasting cannot be conducted. The sample excludes institutionalized patients, and 418 families were excluded for missing data. These data include information for respondents who died during the calendar year, and we made no distinction for consumers insured for part of the year. Families insured for part of the year were categorized as insured. It is possible for a family to appear to have no health insurance coverage if they are enrolled in a plan with indemnity coverage and are reimbursed directly by the insurer. This is also true for families never reaching their deductible threshold.
It is also possible that uninsured consumers have other than self-pay sources of payment if they are eligible for indigent programs or subsidies from charitable organizations.

In this study, the calculation of prescription drug economic burden did not include premium payments. MEPS, unlike the CES, does not collect information regarding prescription drug coverage premium payments, yet these clearly would be considered part of an overall measure of "burden." Additionally, a measure of prescription drug insurance coverage was constructed by identifying families with no evidence of payment from insurance companies. Our proxy measure for uninsured families was achieved by identifying families paying 100\% outof-pocket for prescriptions. This measure was derived from self-reports within MEPS. However, the probability of paying $100 \%$ out-of-pocket favors low-burden families who had fewer prescriptions and, consequently, a higher probability of not reaching their (insurance) deductible threshold.

Additionally, respondents were asked if they experienced an economic barrier to health care in general. This was not a direct measure of access to prescription medications but revealed an

26 Journal of Managed Care Pharmacy JMCP January/February 2003 Vol. 9, No. 1 www.amcp.org 
interesting disparity between elderly and nonelderly families. Nonelderly families experienced higher levels of economic barriers that were more pronounced in the high-burden families.

Finally, unlike many other researchers, we did not censor the data but used ratios of the means within categories to accommodate extreme values. Our calculation of cost per dose also differs. Dose units as presented in Tables 1 and 2 do not necessarily represent a prescribed dose since multiple dose units are sometimes consumed. Cost per day of therapy may be a more appropriate and useful measure, but further work needs to be conducted linking MEPS data with a formulary compendium.

\section{Conclusion}

The often-stated purpose of a drug benefit is to alleviate beneficiaries of the hardship of out-of-pocket expenditures. Even consumers with drug benefits may have inadequate coverage and substantial out-of-pocket costs associated with prescription drug purchases. The value of insurance coverage is diminished if the drug benefit is designed such that significant hardship is borne due to cost sharing.

The study results demonstrate an ability to identify populations with high economic burden with respect to prescription medications. In this study, we used prescription drug economic burden to examine characteristics of prescriptions used by consumers with higher levels of out-of-pocket expenditures compared to income. The constructed prescription drug economic burden score could be used to compare prescription drug benefit proposals using simulation to calculate prescription drug burden for each proposal. The proposal having the most impact on overall average prescription drug burden would represent the more efficient proposal. The strongest argument for examining policy options using prescription drug economic burden is that it presents an opportunity to facilitate effective health care policy decisions by identifying those policy options that reduce average burden and protect consumers from extreme burden.

With no Medicare prescription drug coverage, the presumption is that the population aged $\geq 65$ years, lacking purchasing leverage, is more likely to pay full retail price and, consequently, higher prices. These data suggest that high prescription drug burden was a function of prescription size and cost per prescription, with prescription size showing more drastic differences between the high and low prescription drug-burden subgroups. Future studies should continue to assess factors influencing families' prescription drug economic burden, and the information derived from these studies should be used by benefit planners in designing drug benefits within health insurance plans.

\section{DISCLOSURES}

Funding for this research was provided by the Center for Medication Use, Policy, and Economics and was obtained by author Patrick L. McKercher McKercher served as principal author of the study. Study concept and design, analysis and interpretation of data, and drafting and critical revision of the manuscript was the work of McKercher and authors Stephanie D. Taylor, James A. Lee, Jingdong Chao, and Ritesh N. Kumar.

\section{REFERENCES}

1. U.S. Government Printing Office. Task Force on Prescription Drugs: Final Report (a review of the prescription drug coverage debates at the time of Medicare passage). Washington, D.C.: U.S. Government Printing Office; 1968.

2. Steinberg EP, Gutierrez B, Momani A, Boscarino JA, Neuman P, Deverka P. Beyond survey data: a claims-based analysis of drug use and spending by the elderly. Health Aff. 2000;19:198-211.

3. The Henry J. Kaiser Foundation. Prescription Drug Trends: A Chartbook Menlo Park, California: Kaiser Family Foundation; July 2000;12. Available at: www.kff.org

4. Miller GE, Moeller JF. Outpatient prescription drug prices and insurance coverage: an analysis by therapeutic drug class and user characteristics from the 1996 medical expenditure panel survey. In: Farquhar I, Summers K, Serkin A, eds. Investing in Health: The Social and Economic Benefits of Health Care Innovation. Greenwich, CT.: JAI Press, Inc.; 2001;14:23-57.

5. Poisal JA, Murray L. Growing differences between Medicare beneficiaries with and without drug coverage. Health Aff. 2001;20:74-85.

6. The National Institute for Health Care Management Research and Educational Foundation. Prescription drug expenditures in 2000: the upward trend continues; May 2001. Available at: www.nihcm.org.

7. Distribution of health care expenses, 1996. Rockville, MD: Agency for Healthcare Research and Quality; 2000. MEPS Methodology Report no.11. AHRQ pub. no. 00-0024.

8. Cohen JW, Machin SR, Zuvekas SH, et al. Health care expenses in the United States, 1996. Rockville (MD): Agency Healthcare Research and Quality; 2000. MEPS Research Findings 12. AHRQ pub. no. 01-0009.

9. Reinhardt UE. Perspectives on the pharmaceutical industry. Health Aff. 2001;20:136-49.

10. Davis M, Poisal J, Chulis G, et al., Prescription drug coverage, utilization, and spending among Medicare beneficiaries. Health Aff. 1999;18:231-43

11. Mueller C, Schur C, O'Connel J. Prescription drug spending: the impact of age and chronic disease status. Am J Pub Health. 1997;87:1626-29.

12. Garfinkel SA, Riley GF, Iannacchione VG. High-cost users of medical care Health Care Financing Rev. 1988;9:41-52.

13. Chrischilles EA, Foley DJ, Wallace RB, et al. Use of medications by persons 65 and over: data from the established populations for epidemiologic studies of the elderly. J Gerontol. 1992;47:M137-M144

14. Rogowski J, Lillard LA, Kington R. The financial burden of prescription drug use among elderly persons. Gerontologist. 1997;37:475-82.

15. Crystal S, Johnson RW, Harman J, Sambamoorthi U, Kumar R. Out-of-pocket health care costs among older Americans. J Gerontol. 2000;55B:S51-S62.

16. Gross DJ, Alecxih L, Gibson MJ, et al. Out-of-pocket health spending by poor and near-poor elderly Medicare beneficiaries. Health Serv Res 1999;34:241-54

17. Lillard LA, Rogowski J, Kington R. Insurance coverage for prescription drugs: effects on use and expenditures in the Medicare population. Med Care. 1999;37:926-36

18. Agency information collection activities: proposed collection; comment request. Federal Register: April 3, 2002;67(64):15812-814.

19. Cunningham PJ. Affording prescription drugs: not just a problem for the elderly. Center for Studying Health System Change. Research Report no. 5, April 2002.

20. Overview of the MEPS Web Site. October 2002. Agency for Healthcare Research and Quality, Rockville, MD. Available at: http://www.ahrq.gov/data/mepsweb.htm. Accessed November 2002

21. Moeller JF, Stagnitti MN, Horan E, et al. Outpatient prescription drugs: 
data collection and editing in the 1996 Medical Expenditure Panel Survey (HC-010A). Rockville (MD): Agency for Healthcare Research and Quality; 2001. MEPS Methodology Report no. 12. AHRQ pub. no. 01-002.

22. Moon M, Kuntz C, Pounder L. Protecting low-income Medicare beneficiaries. 1996. Washington, DC: The Commonwealth Fund. (Publication no. 195).

23. Consumer Expenditure Survey, U.S. Bureau of Labor Statistics. Available at: www.bls.gov/cex/home.html. Accessed May 2002

24. Multum Information Services Inc, Denver, Colorado. Available at: www.Multum.com.

25. Lee JA, McKercher PL. Statistical comparison of consumer drug expenditures and discretionary purchases to assess drug affordability. Clin Ther. 2002;24:1003-16

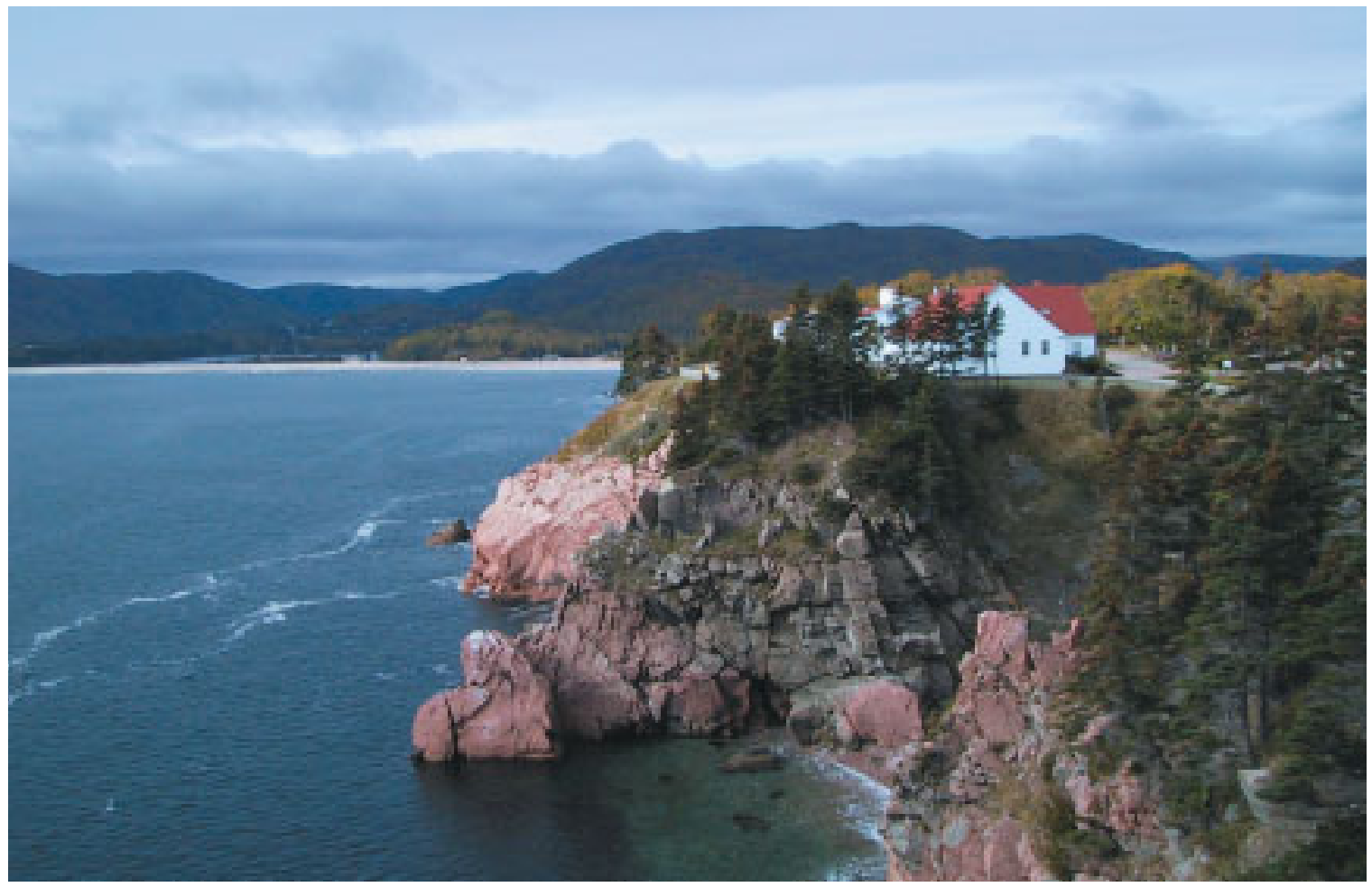

Ingonish, Nova Scotia

Photograph by Neil J. MacKinnon, $\mathrm{PhD}, \mathrm{RPh}$ 